\title{
Oospore Germination of Aphanomyces euteiches in Root Exudates and on the Rhizoplanes of Crop Plants
}

\author{
H. Shang, C. R. Grau, and R. D. Peters, Department of Plant Pathology, University of Wisconsin-Madison, Rus- \\ sell Laboratories, 1630 Linden Drive, Madison 53706
}

\begin{abstract}
Shang, H., Grau, C. R., and Peters, R. D. 2000. Oospore germination of Aphanomyces euteiches in root exudates and on the rhizoplanes of crop plants. Plant Dis. 84:994-998.

A technique was developed that allows prolific production, easy collection, and increased germination frequency of single oospores of Aphanomyces euteiches. The influence of root exudates and roots of various plant species, including pea, bean, alfalfa, oat, soybean, corn, and tomato, on germination of A. euteiches oospores also was studied. Compared with a sterile, deionized water control, root exudates from several hosts were only slightly effective in stimulating oospore germination, since only 0 to $11.1 \%$ of oospores exposed to various exudates germinated. By contrast, oospores placed directly on plant roots germinated at higher frequencies. Oospores of pea pathotype isolates P30 and P46 germinated at a greater frequency (30.6 to $61.1 \%$ ) on pea, bean, and oat roots than on roots of any of the other plant species tested. Oospores of bean pathotype isolates GB33 and GB71 had a higher germination frequency (47.2 to $52.8 \%$ ) on bean roots than on the roots of the other plant species tested. A higher percentage of oospores germinated if placed on lateral roots as opposed to taproots of pea and bean. A higher percentage of oospores of bean pathotype isolates and one pea pathotype isolate germinated on 10-day-old rather than on 20-day-old roots of bean. Therefore, pea and bean roots can be used effectively to germinate oospores of pea and bean isolates of A. euteiches, respectively. This technique will be valuable for studies of sexual reproduction and genetics of A. euteiches.
\end{abstract}

Aphanomyces euteiches Drechs. causes root rot of many economically important crops, including peas (Pisum sativum L.), beans (Phaseolus vulgaris L.), and alfalfa (Medicago sativa L.). Oospores are considered the primary source of inoculum and can survive in soil for many years, reducing the value of crop rotation as a means to control this pathogen (18).

Knowledge about the germination of $A$. euteiches oospores in the root zones of various crops is limited, because it is typically difficult to stimulate germination. There are few studies describing how biological, chemical, and physical methods affect oospore germination of Aphanomyces species. Oospores of A. euteiches are known to survive in plant debris in soil, and to germinate in leachate from pea grown in sand and the plant rhizosphere $(16,17)$. Yang (29) reported that oospores treated with chymotripsin germinated at a frequency of up to $50 \%$. When hydrochloric acid was added to lower the $\mathrm{pH}$ of tap water to 3.3 to $5.1,40 \%$ of A. euteiches oospores germinated (16). In some isolates of A. euteiches, approximately $90 \%$ of

Corresponding author: C. R. Grau

E-mail: cg6@plantpath.wisc.edu

Accepted for publication 26 May 2000.

Publication no. D-2000-0717-01R

(C) 2000 The American Phytopathological Society oospores germinated within 10 days after treatment with 2,000-lx white fluorescent light (30). Other methods such as freezing or alternate freezing and thawing did not stimulate oospore germination of $\mathrm{A}$. $\mathrm{eu}$ teiches (16). In $A$. raphani Kendrick, a pathogen of radish, $14 \%$ of oospores germinated adjacent to radish seedling roots (9).

There have been several studies on oospore germination of other oomycetes such as Phytophthora and Pythium. Root extracts and root exudates of alfalfa and dung infusion and potato-soil leachate preparations produced three- to fourfold higher germination rates of oospores of Phytophthora spp. than controls $(7,8,27)$. The treatment of oospores of Phytophthora and Pythium with $\mathrm{KMnO}_{4}(1,4,11)$ or the enzymes hemicellulase and cellulase (25) also induced oospore germination. However, many physical methods, including freezing and thawing, heat shock, and exposure to light, were found to be ineffective at stimulating oospore germination (2).

Oospore isolation techniques are typically labor-intensive. In many cases, oospores prepared by blending cultures followed by filtration and centrifugation $(8,9)$ are commonly contaminated with bacteria and not free of mycelial strands. Furthermore, generation of viable cultures of oomycete pathogens from single, germinated oospores can be difficult.

The use of published protocols $(2,7,8,16,17,29,30)$ to germinate oospores of A. euteiches has yielded variable and generally unsatisfactory results in our laboratory. Therefore, the goal of this study was to test two methods for their ability to enhance the recovery and subsequent germination of oospores of A. euteiches. We report here the development of an effective technique to prepare, germinate, and recover single, germinated oospores. This method could also be useful for single oospore preparation of other oomycetes.

\section{MATERIALS AND METHODS}

Isolates. Isolates of A. euteiches were obtained from a bean and pea field near Evansville (P30), from a pea field near Antigo (P46), and from bean fields near Menomonie (GB33) and Hancock (GB71), WI. Isolates were recovered from soil using host plants as bait; isolates P30 and P46 were obtained from pea roots; whereas isolates GB33 and GB71 were obtained from green bean roots. A semiselective medium was used to isolate A. euteiches from symptomatic roots (19). Isolates recovered from pea and bean were selected based on previous reports of diversity in pathogenicity and other traits (20). Isolates P30 and P46 and isolates GB33 and GB71 were classified as "pea pathotypes" and "bean pathotypes," respectively, based on their pathogenicity on these hosts (data not shown). All isolates were maintained on cornmeal agar (CMA; Difco, Detroit, MI) and transferred to fresh CMA at 6-month intervals. Isolates were characterized as $A$. euteiches according to the descriptions of Dick (6) and Scott (23).

Oospore production. An isolate of $A$. euteiches was transferred to two sites, approximately $4 \mathrm{~cm}$ apart, in a petri dish $(60$ $\times 15 \mathrm{~mm}$ ) containing CMA. A 2-cm-wide agar strip was then removed from the center of the petri dish to allow mycelia of the isolate to extend from both inoculated sites, grow on the agar-free surface of the dish, and produce oospores (Fig. 1A). Oospores were formed 14 days after inoculation at room temperature. Using a sterile surgical knife, single oospores were removed with the aid of a dissecting microscope and were placed on $1 \mathrm{~mm}^{3}$ agar blocks in petri dishes (Fig. 1B). The petri dishes were then sealed with Parafilm (Parafilm "M" Laboratory Film, American National Can, Chicago, IL) and stored at $-20^{\circ} \mathrm{C}$ to ensure that any residual mycelium was destroyed. Studies on long-term storage of cultures of A. euteiches indi- 
cated that the pathogen could not be recovered after exposure of mycelium to freezing temperatures (R. D. Peters, unpublished data).

Root exudate production and germination tests. Root exudates were produced using pea (cvs. 77 Early Perfection [77EP] and MN313), bean (cv. Early Gallatin [EG]), oat (Avena sativa cv. Prairie), alfalfa (cv. Saranac), soybean (Glycine max (L.) Merril. cv. BSR101), tomato (Lycopersicon esculentum L. cv. Rutgers), and corn (Zea mays L. cv. Radiance). Seeds of each species were rinsed briefly with $95 \%$ ethanol, soaked in $0.2 \% \mathrm{HgCl}$ for $5 \mathrm{~min}$, and rinsed with sterile, deionized water three times. Seeds were placed in sterile glass flasks $(100 \mathrm{ml}, 10$ seeds per flask) containing $5 \mathrm{ml}$ of sterile, deionized water. Flasks were then covered with sterile aluminum foil and kept at room temperature in the dark for 14 days to allow germination and root development. To collect exudates, the cover was removed carefully and $5 \mathrm{ml}$ of a sterile lake water:deionized water mixture (1:1) was added. One hour after incubation at room temperature, the exudate solution from each flask was removed with a sterile Pasteur pipet and stored at $4^{\circ} \mathrm{C}$.

To test the effect of each of the root exudates on oospore germination, one to three drops of root exudate were delivered to each oospore placed on agar blocks in a petri dish so that the oospore was covered by the exudate. The dish was then sealed with Parafilm and placed in the dark at room temperature. Oospore germination was evaluated under a dissecting microscope 10 days after incubation.

Plant preparation and oospore germination tests. Seeds of pea, bean, oat, alfalfa, soybean, tomato, and corn as described above were moistened using 95\% ethanol, surface-sterilized with $0.2 \% \mathrm{HgCl}$ for $5 \mathrm{~min}$, rinsed three times using sterile, deionized water, and placed on sterile filter paper in 250-ml beakers. The beakers were then covered with sterile aluminum foil and kept at room temperature in the dark. Six days later, a seedling was removed from the beaker and laid on a sterile moistened filter paper in a petri dish (Fig. 1C). A total of six single oospores were removed from agar blocks and placed on different lateral roots of each seedling. The petri dish was then sealed with Parafilm and placed in the dark at room temperature. Oospore germination was evaluated 10 days after inoculation. Taproots and lateral roots of pea and bean plants were tested for their efficiency in promoting oospore germination. Lateral roots of pea (77EP and MN313), bean, alfalfa, oat, soybean, corn, and tomato were used to determine how they affected oospore germination. For testing the influence of plant age on oospore germination, lateral roots of 10- and 20-day-old pea (77EP) and bean were used.

To assess germination of oospores on plant roots, inoculated roots were washed with tap water, blot dried with paper towels, and placed in tubes containing $10 \%$
$\mathrm{KOH}$ at $60^{\circ} \mathrm{C}$ overnight. The roots were then rinsed with water and neutralized with $10 \% \mathrm{HCl}$, stained with $0.05 \%$ trypan blue in lactoglycerin at $60^{\circ} \mathrm{C}$ for $20 \mathrm{~min}$, and destained with lactoglycerin. The samples were then observed under a dissecting microscope for the presence of mycelium inside or on the roots. Twelve oospores were inoculated on two plants as a replicate; there were three replicates per treatment.

Experimental design and statistical analysis. Each study was arranged as a completely randomized design with two repetitions of the experiment. Data from separate experiments were combined after tests for homogeneity of variance showed nonsignificant values. Nontransformed data were analyzed with SAS Version 6.10 (SAS Institute, Cary, NC) using analysis of variance and Fisher's least significant difference (LSD, $P=0.05$ ) for comparison of treatment means.

\section{RESULTS}

Influence of plant root exudates on oospore germination. Oospores of both pea pathotype isolates (P30 and P46) and bean pathotype isolates (GB33 and GB71) germinated differently in root exudates from several plant species (Table 1). Oospores of the pea pathotype isolates (P30 and P46) germinated similarly in pea (77EP and $\mathrm{MN} 313 ; 11.1 \%$ ), bean, and soybean root exudates (5.6 to $8.3 \%$ ), but at a significantly lower frequency in alfalfa and tomato root exudates (2.8\%). Oospores

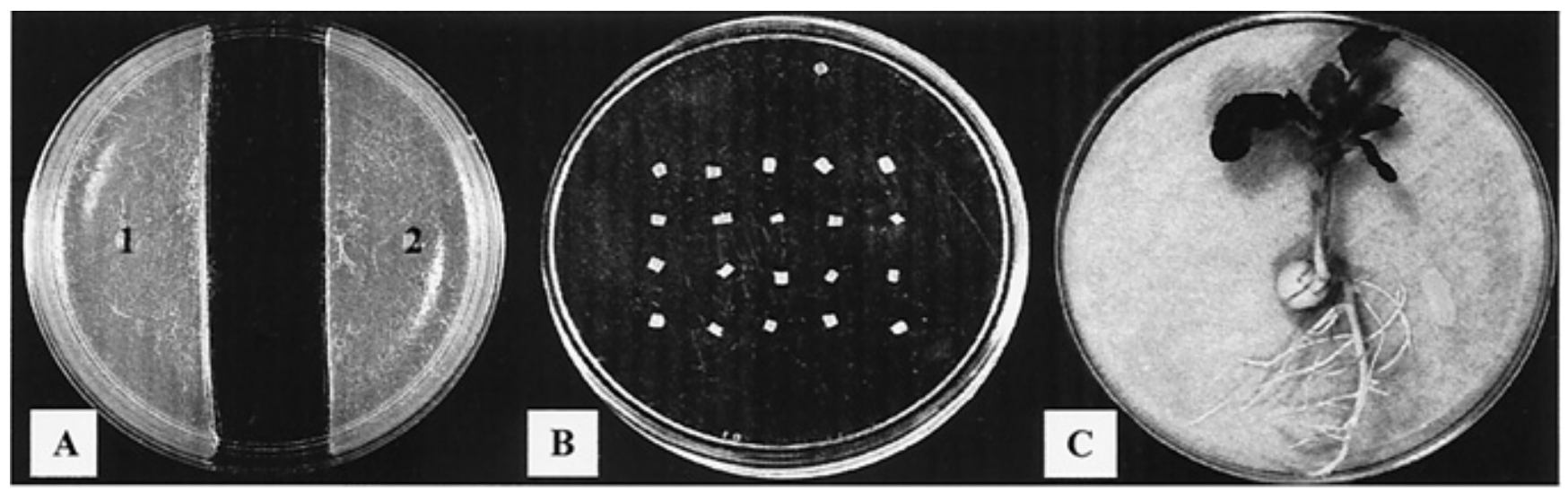

Fig. 1. Production, recovery, and germination of Aphanomyces euteiches oospores. (A) A petri dish of cornmeal agar with the center agar strip removed for single oospore production of $A$. euteiches. The same isolate was inoculated to sites 1 and 2, and oospores were produced in the agar-free area of the dish after incubation. (B) Single oospore storage on agar blocks in a petri dish. (C) A 10-day-old pea plant; plant roots were used to germinate oospores of $A$. euteiches.

Table 1. Germination percentage of oospores of Aphanomyces euteiches exposed to selected plant root exudates ${ }^{z}$

\begin{tabular}{|c|c|c|c|c|c|c|c|c|c|}
\hline \multirow[b]{2}{*}{ Isolates } & \multicolumn{9}{|c|}{ Root exudates from various hosts } \\
\hline & Pea 77EP & Pea MN313 & Bean & Alfalfa & Oat & Soybean & Corn & Tomato & Water \\
\hline P30 & $11.1 \mathrm{a}$ & $11.1 \mathrm{a}$ & $5.6 \mathrm{ab}$ & $2.8 \mathrm{~b}$ & $5.6 \mathrm{ab}$ & $5.6 \mathrm{ab}$ & $5.6 \mathrm{ab}$ & $2.8 \mathrm{~b}$ & $0.0 \mathrm{~b}$ \\
\hline P46 & $11.1 \mathrm{a}$ & $11.1 \mathrm{a}$ & $5.6 \mathrm{ab}$ & $2.8 \mathrm{~b}$ & $2.8 \mathrm{~b}$ & $8.3 \mathrm{ab}$ & $0.0 \mathrm{~b}$ & $2.8 \mathrm{~b}$ & $0.0 \mathrm{~b}$ \\
\hline GB33 & $2.8 \mathrm{~b}$ & $2.8 \mathrm{~b}$ & $8.3 \mathrm{a}$ & $5.6 \mathrm{ab}$ & $2.8 \mathrm{~b}$ & $0.0 \mathrm{~b}$ & $0.0 \mathrm{~b}$ & $0.0 \mathrm{~b}$ & $0.0 \mathrm{~b}$ \\
\hline GB71 & $2.8 \mathrm{a}$ & $2.8 \mathrm{a}$ & $2.8 \mathrm{a}$ & $2.8 \mathrm{a}$ & $2.8 \mathrm{a}$ & $2.8 \mathrm{a}$ & $0.0 \mathrm{~b}$ & $0.0 \mathrm{~b}$ & $0.0 \mathrm{~b}$ \\
\hline
\end{tabular}

${ }^{\mathrm{z}}$ Data represent means of two experiments with three replicates each. Means within a row followed by the same letter are not significantly different as determined by the least significant difference test $(P=0.05)$. 
of P46 did not germinate in corn root exudate and germinated in oat exudate at a significantly lower percentage than that in pea exudates. Bean pathotype isolate GB33 had significantly greater oospore germination in bean than in pea and oat root exudates. Conversely, oospores of the other bean pathotype (GB71) germinated at the same low frequency in root exudates from pea, bean, alfalfa, oat, and soybean $(2.8 \%)$. Oospores of GB33 or GB71 did not germinate in exudates of corn and tomato roots. No pea cultivar effect was seen on oospore germination of either pea or bean isolates. Although oospore germination in root exudates was low $(\leq 11.1 \%)$ for all isolates, more oospores of pea pathotypes germinated compared with oospores of bean pathotypes. No germination of any isolate was observed in deionized, sterile water controls.

Influence of root position on oospore germination. A greater percentage of oospores germinated on lateral and taproots of pea and bean than germinated in root exudates for most of the isolates tested (Tables 1 and 2). More oospores of both pea isolates (P30 and P46) and bean isolates (GB33 and GB71) germinated on lateral roots (33.3 to $72.2 \%$ ) than on taproots of pea and bean (0 to 16.7\%). Oospore germination of isolates P30 (47.2 to $58.3 \%)$ and P46 (61.1 to $72.2 \%$ ) was similar on lateral roots of pea and bean. However, lateral roots of bean were significantly better in stimulating oospore germination of the two bean pathotypes (63.9\% for GB33 and 55.6\% for GB71) than the lateral roots of pea $(33.3 \%$ for GB33 and $37.2 \%$ for GB71). Low germination (0 to $5.6 \%$ ) was observed in sterile, deionized water controls.

Influence of plant species on oospore germination. Oospores of $A$. euteiches germinated at different frequencies on the roots of various plant species used in this study (Table 3 ). When placed on the lateral roots of pea (both susceptible cultivar 77EP and resistant cultivar MN313) and bean, oospores of the two pea isolates germinated at a significantly higher percentage (36.1 to $44.4 \%$ for P30 and 47.2 to $61.1 \%$ for P46) than if placed on lateral roots of alfalfa, soybean, corn, or tomato (8.3 to $16.7 \%$ for P30 and 19.4 to $22.2 \%$ for P46). However, a significantly higher germination percentage of oospores of the two bean isolates was obtained only on bean roots (47.2\% for GB33 and 52.8\% for GB71) compared with the roots of other plants. GB33 and GB71 had less than $10 \%$ oospore germination on lateral roots of corn and tomato. No significantly different effect was observed between susceptible cultivar 77EP and resistant cultivar MN313 on oospore germination percentage of all four isolates tested. No or low oospore germination (0 to $2.8 \%$ ) was observed in sterile, deionized water controls.

Influence of pea and bean of different ages on oospore germination. Lateral root age had no significant effect on oospore germination of pea isolates P30 and P46 (Table 4). On the contrary, for bean isolates, oospore germination was greater on 10 -day-old bean roots $(52.8 \%$ for GB33 and $61.1 \%$ for GB71) than on 20-day-old bean roots (36.1\% for GB33 and $41.6 \%$ for GB71). In addition, oospores of P30 and P46 germinated equally well on both pea (10- and 20-day-old) and 10-day-old bean roots (47.2 to $69.4 \%$ ), while GB33 and GB71 had a significantly lower oospore germination percentage ( 22.2 to $38.9 \%$ ) on pea roots (10- and 20-day-old) than on 10day-old bean roots.

\section{DISCUSSION}

An effective technique was developed for formation, recovery, and germination of

Table 2. Germination percentage of oospores of Aphanomyces euteiches on lateral and taproots of pea and bean ${ }^{\mathrm{z}}$

\begin{tabular}{lccccc}
\hline & \multicolumn{5}{c}{ Root position and plant species } \\
\cline { 2 - 6 } Isolates & Pea lateral root & Pea taproot & Bean lateral root & Bean taproot & Water \\
\hline P30 & $58.3 \mathrm{a}$ & $5.6 \mathrm{~b}$ & $47.2 \mathrm{a}$ & $2.8 \mathrm{~b}$ & $0.0 \mathrm{~b}$ \\
P46 & $72.2 \mathrm{a}$ & $11.1 \mathrm{~b}$ & $61.1 \mathrm{a}$ & $13.9 \mathrm{~b}$ & $5.6 \mathrm{~b}$ \\
GB33 & $33.3 \mathrm{~b}$ & $0.0 \mathrm{c}$ & $63.9 \mathrm{a}$ & $16.7 \mathrm{c}$ & $0.0 \mathrm{c}$ \\
GB71 & $37.2 \mathrm{~b}$ & $11.1 \mathrm{c}$ & $55.6 \mathrm{a}$ & $16.7 \mathrm{c}$ & $2.8 \mathrm{c}$ \\
\hline
\end{tabular}

${ }^{\mathrm{z}}$ Data represent means of two experiments with three replicates each. Means within a row followed by the same letter are not significantly different as determined by the least significant difference test $(P=0.05)$.

single oospores of A. euteiches. This technique allows prolific production as well as easy and accurate collection of sexual progeny. It also assures that harvested oospores are free of mycelia and has potential for accurate tracing of the parental mycelia that produce hybrid oospores. The technique has been successfully used to produce hybrid progeny resulting from mating pea and bean pathotype isolates (24). Therefore, studies on genetic recombination in A. euteiches are facilitated.

With the aid of the oospore isolation method, we studied the influence of root exudates, contact with different root positions, different plant species, and different ages of plants on germination of the isolated oospores of A. euteiches. This study was initiated after we found that many of the published methods $(2,7,8,16,17,29,30)$ for germinating oospores of A. euteiches, Phytophthora, or Pythium were not repeatable. For example, methods including direct germination in deionized water or lake water, and germination after treatment with freeze-thaw cycles, heat treatment (30, 35, and $40^{\circ} \mathrm{C}$ ), hydrochloric acid treatment, and $\mathrm{KMnO}_{4}$ were attempted. Oospore activation (swollen oospore) was observed in the $\mathrm{KMnO}_{4}$ treatment, but oospore germination was not common. It is unclear why our attempts at using published protocols were unsuccessful; however, the discrepancy may be caused by the differences between our isolates and those used by other researchers $(16,17,29,30)$. It is also probable that specific protocols for oospore germination are not applicable to all oomycetes.

In our study, most root exudates tested stimulated oospore germination, and some induced significantly higher percentages of germination than a water control, suggesting that some factors stimulating oospore germination exist in the root exudate, and that such factors are water soluble and somewhat host-specific. Overall, germination was low (0 to $11.1 \%)$. In addition, active cultures of $A$. euteiches derived from germinated oospores in root exudates were often contaminated by bacteria, therefore limiting the use of root exudates as an effective means to recover $A$. euteiches isolates.

Root type and age had an effect on oospore germination of $A$. euteiches. Oospore germination was significantly higher on lateral roots than on taproots; metabolic

Table 3. Germination percentage of oospores of Aphanomyces euteiches in the rhizoplane of several plant species ${ }^{\mathrm{z}}$

\begin{tabular}{lccccccccc}
\hline & \multicolumn{9}{c}{ Plant species } \\
\cline { 2 - 7 } Isolates & Pea 77EP & Pea MN313 & Bean & Alfalfa & Oat & Soybean & Corn & Tomato & Water \\
\hline P30 & $44.4 \mathrm{a}$ & $38.9 \mathrm{a}$ & $36.1 \mathrm{a}$ & $16.7 \mathrm{~b}$ & $30.6 \mathrm{ab}$ & $13.9 \mathrm{bc}$ & $8.3 \mathrm{bc}$ & $8.3 \mathrm{bc}$ & $0.0 \mathrm{c}$ \\
P46 & $61.1 \mathrm{a}$ & $55.6 \mathrm{a}$ & $47.2 \mathrm{a}$ & $19.4 \mathrm{~b}$ & $44.4 \mathrm{a}$ & $22.2 \mathrm{~b}$ & $19.4 \mathrm{~b}$ & $22.2 \mathrm{~b}$ & $2.8 \mathrm{~b}$ \\
GB33 & $22.2 \mathrm{~b}$ & $19.4 \mathrm{bc}$ & $47.2 \mathrm{a}$ & $13.9 \mathrm{bcd}$ & $25.0 \mathrm{~b}$ & $13.9 \mathrm{bcd}$ & $8.3 \mathrm{~cd}$ & $5.6 \mathrm{~cd}$ & $0.0 \mathrm{~d}$ \\
GB71 & $30.6 \mathrm{bc}$ & $36.1 \mathrm{~b}$ & $52.8 \mathrm{a}$ & $33.3 \mathrm{~b}$ & $16.7 \mathrm{~cd}$ & $19.4 \mathrm{~cd}$ & $8.3 \mathrm{~d}$ & $5.6 \mathrm{~d}$ & $0.0 \mathrm{~d}$ \\
\hline
\end{tabular}

${ }^{\mathrm{z}}$ Data represent means of two experiments with three replicates each. Means within a row followed by the same letter are not significantly different as determined by the least significant difference test $(P=0.05)$. 
products excreted from the young cells of lateral roots are possibly different from those of mature cells of taproots or perhaps are released in greater concentration, resulting in compatible interactions between lateral roots and the oospores. The results also revealed that the effect of pea root age on oospore germination was not significant. Ten-day-old bean roots, however, stimulated significantly more oospores to germinate than did 20-day-old bean roots for isolates P30, GB33, and GB71. It was noted that bean plants grew much faster than pea plants in a 10- to 20-day period, and that therefore the physiological difference between 10- and 20-day-old bean roots might be greater than that between 10- and 20-day-old pea roots, possibly resulting in the observed differences in oospore germination.

Different levels of host preference were observed. In general, more oospores germinated on roots of preferred host plants (pea and bean) than on nonpreferred hosts (soybean, corn, or tomato) except for alfalfa and oat. Significantly more oospores of bean pathotype isolates (GB33 and GB71) germinated on bean than on pea roots, confirming the preference of bean pathotype isolates for bean plants $(10,14,20)$. However, no significant difference in oospore germination was observed for pea pathotype isolates P30 and P46 on pea and bean roots, which is consistent with the wider host range of pea pathotype isolates $(10,14,20)$.

On soybean, corn, and tomato roots, low percentages (5.6 to $22.2 \%$ ) of oospore germination were observed for both the pea and bean pathotype. This is probably advantageous for survival of the pathogen because the germination potential of oospores would not be squandered in the absence of a preferred host. Oospores can survive exposure to adverse conditions and maintain infectivity in soils (26). Conversely, some germination on the roots of nonpreferred hosts would enable the pathogen to colonize plant tissues and reproduce when no preferred host is present. Various studies document the colonization and formation of oospores (often in low number) of isolates of A. euteiches in the roots of a variety of plant species $(3,26)$.

Oospores of pea pathotype isolates germinated well on oat roots (Table 3 ). Oat

Table 4. Germination percentage of oospores of Aphanomyces euteiches on pea and bean roots of different ages ${ }^{2}$

\begin{tabular}{|c|c|c|c|c|}
\hline \multirow[b]{2}{*}{ Isolates } & \multicolumn{2}{|c|}{ Pea } & \multicolumn{2}{|c|}{ Bean } \\
\hline & 10 day & 20 day & 10 day & 20 day \\
\hline P30 & $61.1 \mathrm{a}$ & $55.6 \mathrm{a}$ & $47.2 \mathrm{a}$ & $30.5 \mathrm{~b}$ \\
\hline P46 & $69.4 \mathrm{a}$ & $58.3 \mathrm{ab}$ & $50.0 \mathrm{ab}$ & $38.9 \mathrm{~b}$ \\
\hline GB33 & $30.6 \mathrm{~b}$ & $22.2 \mathrm{~b}$ & $52.8 \mathrm{a}$ & $36.1 \mathrm{~b}$ \\
\hline GB71 & $38.9 \mathrm{bc}$ & $22.2 \mathrm{c}$ & $61.1 \mathrm{a}$ & $41.6 \mathrm{~b}$ \\
\hline
\end{tabular}

${ }^{\mathrm{z}}$ Data represent means of two experiments with three replicates each. Means within a row followed by the same letter are not significantly different as determined by the least significant difference test $(P=0.05)$ crops grown prior to peas have been shown to reduce the incidence and severity of pea root rot $(12,28)$ and lower inoculum denrelease of fungitoxic-fungistatic compounds which lyse zoospores and inhibit oospore formation and germination $(5,28)$. However, the results would indicate that, in addition to the release of fungistatic compounds, the use of oats as part of a cropping system may encourage oospore gerin the absence of a preferred host. Oat roots are colonized by $A$. euteiches, but support minimal sexual reproduction (3). Therefore, while nonspecific effects in these tests may indicate that factors that stimulate oospore germination are common to many plant species, specific interaction of some hosts and isolates may be due to specific metabolic products that stimulate the oospores of the isolates tested. This information is important to better design and utilize crop rotation and crop sequences to control this plant pathogen.

The resistant pea line MN313 did not inhibit oospore germination in both root exudate and plant root studies. By contrast, zoospore germination was reduced in seedling exudates from resistant pea lines as reported by Kraft and Boge (13). This suggests that the resistance mechanism may be expressed at stages of the infection process other than inhibition of oospore germination and primary infection. In alfalfa, it was observed that root exudates from cultivars either resistant or susceptible to Phytophthora medicaginis Hansen et Maxwell enhanced oospore germination of this pathogen (7). The lack of an effect by the resistant germ plasm is not surprising, since resistance in alfalfa to $P$. medicaginis is expressed within root tissue (15). Nonspecific interactions in these tests may indicate that the factors that stimulate oospore germination are not linked with disease susceptibility.

It is unknown what specific factor(s) triggered oospore germination. Schroth and Hildebrand (22) reported that plant root extracts and exudates contain a wide variety of compounds such as amino acids, enzymes, alkaloids, nucleotides, and inorganic ions. Rovira (21) found that pea roots exude 22 different amino acids and sity levels (28), presumably due to the mination, thereby reducing inoculum levels sugars, glycosides, organic acids, vitamins, sugar (probably glucose). In alfalfa root extract and exudates, the cationic fraction that contained amino acids stimulated oospore germination (7). Aspartic acid, singly and in combination with certain other amino acids, increased oospore germination when added to dilute root exudate but was not active in water. Ribose from the neutral fraction of alfalfa root extract or exudate increased germination slightly (7).

The primary events responsible for initiation of oospore germination remain largely speculative. Although the controlled experimental methods used in this study may not reflect actual field conditions, the use of this plant root method may be useful in studying the effect of physical and chemical factors on germination of $A$. euteiches oospores. The technique will certainly facilitate studies on variation in A. euteiches generated by sexual recombination.

\section{ACKNOWLEDGMENTS}

We thank Elizabeth Hinkens for excellent technical assistance.

\section{LITERATURE CITED}

1. Ann, P. J., and Ko, W. H. 1988. Induction of oospore germination of Phytophthora parasitica. Phytopathology 78:335-338.

2. Ayers, W. A., and Lumsden, R. D. 1975. Factors affecting production and germination of oospores of three Pythium species. Phytopathology 65:1094-1100.

3. Carlson, L. E. 1965. Studies on the root rot of peas caused by Aphanomyces euteiches Drechs. Ph.D. thesis. University of Minnesota, St. Paul.

4. Chang, T. T., and Ko, W. H. 1991. Factors affecting germination of oospores of Phytophthora infestans. J. Phytopathol. 133:29-35.

5. Deacon, J. W., and Mitchell, R. T. 1985 Toxicity of oat roots, oat root extracts, and saponins to zoospores of Pythium spp. and other fungi. Trans. Br. Mycol. Soc. 84:479487.

6. Dick, M. W. 1971. Oospore structure in Aphanomyces. Mycologia 63:686-688.

7. El-Hamalawi, Z. A., and Erwin, D. C. 1986. Components in alfalfa root extract and root exudate that increase oospore germination of Phytophthora megasperma f. sp. medicaginis. Phytopathology 76:508-513.

8. Forster, H., Ribeiro, O. K., and Erwin, D. C. 1983. Factors affecting oospore germination of Phytophthora megasperma f. sp. medicaginis. Phytopathology 73:442-448.

9. Ghafoor, A. 1964. Radish, black-root fungus: Host range, nutrition, and oospore production and germination. Phytopathology 54:11671171.

10. Grau, C. R., Muehlchen, A. M., Tofte, J. E., and Smith, R. R. 1991. Variability in virulence of Aphanomyces euteiches. Plant Dis. 75:1153-1156.

11. Guo, L. Y., and Ko, W. H. 1994. Factors affecting oospore germination of heterothallic Pythium splendens. Mycologia 86:777-780.

12. Kazmar, E. R. 1995. Effect of intercropped oats on Aphanomyces root rot of pea. M.Sc. thesis. University of Wisconsin-Madison.

13. Kraft, J. M., and Boge, W. L. 1996. Identification of characteristics associated with resistance to root rot caused by Aphanomyces euteiches in pea. Plant Dis. 80:1383-1386.

14. Malvick, D. K., Grau, C. R., and Percich, J. A. 1998. Characterization of Aphanomyces euteiches strains based on pathogenicity tests 
and random amplified polymorphic DNA analyses. Mycol. Res. 102:465-475.

15. Miller, S. A., and Maxwell, D. P. 1984. Ultrastructure of susceptible, host resistant, and nonhost resistant interaction of alfalfa with Phytophthora megasperma. Can. J. Bot. 62:117-128.

16. Olofsson, J. 1968. Influence of hydrogen-ion concentration on germination of naturally produced oospores of Aphanomyces euteiches. Plant Dis. Rep. 52:264-267.

17. Percich, J., and Mitchell, J. 1976. Germination of oospores of Aphanomyces euteiches in soil in contact with roots. (Abstr.) Phytopathology 3(Suppl.):280.

18. Pfender, W. F. 1984. Aphanomyces root rot. Pages 25-28 in: Compendium of Pea Diseases. D. J. Hagedorn, ed. American Phytopathological Society, St. Paul, MN

19. Pfender, W. F., Delwiche, P. A., Grau, C. R., and Hagedorn, D. J. 1984. A medium to enhance recovery of Aphanomyces from infected plant tissue. Plant Dis. 68:845-847.

20. Pfender, W. F., and Hagedorn, D. J. 1982. Aphanomyces euteiches f. sp. phaseoli, a causal agent of bean root and hypocotyl rot. Phytopathology 72:306-310.

21. Rovira, A. D. 1956. Plant root excretions in relation to the rhizosphere effect. I. The nature of root exudate from oats and peas. Plant Soil 7:178-194.

22. Schroth, M. N., and Hildebrand, D. C. 1964. Influence of plant exudates on root-infecting fungi. Annu. Rev. Phytopathol. 54:101-132.

23. Scott, W. W. 1961. A monograph of the genus Aphanomyces. Virginia Agricultural Experiment Station, Blacksburg.

24. Shang, H., Grau, C. R., and Peters, R. D. Evidence of gene flow between pea and bean pathotypes of Aphanomyces euteiches. Can. J. Plant Pathol. In press.

25. Sharma, N. 1990. Aseptic germination of oospores of Phytophthora palmivora. Can. J. Bot. 68:2548-2552.
26. Sherwood, R. T., and Hagedorn, D. J. 1962 Studies on the biology of Aphanomyces euteiches. Phytopathology 52:150-154.

27. Smoot, J. J., Gough, F. J., Lamey, H. A Eichenmuller, J. J., and Gallegly, M. E. 1958 Production and germination of oospores of Phytophthora infestans. Phytopathology 48:165-171.

28. Williams-Woodward, J. L., Pfleger, F. L. Fritz, V. A., and Allmaras, R. R. 1997. Green manures of oat, rape and sweet corn for reducing common root rot in pea caused by Aphanomyces euteiches. Plant Soil 188:43-48.

29. Yang, C. Y. 1970. Enzyme-induced germination of Aphanomyces oospores. (Abstr.) Phytopathology 60:1320.

30. Yokosawa, R., and Kuninaga, S. 1983. Effects of light on oospore germination of Aphanomyces euteiches isolated from pea root rot field soil in Furano, Hokkaido, and from pea field soil of Miyakejima, Japan. Ann. Phytopathol. Soc. Jpn. 49:56-62. 